\title{
The Role of Cross-linguistic Experience on English Idiom and Proverb Comprehension: A Case of Iranian Turkish Learners of English as a Foreign and Third Language
}

\author{
Behnaz Moein \\ English Language Department, University of Zanjan, Iran \\ Robab Khosravi \\ English Language Department, University of Zanjan, Iran \\ Hooshang Yazdani \\ Department of English Language and Literature, Arak University, Iran

\begin{abstract}
The current study aimed to establish whether linguistic background influences Iranian EFL learners' English proverb and idiom comprehension. The specific research question was whether there is a statistically significant difference between the performances of Persian monolinguals and Persian-Turkish bilinguals in idiom-proverb comprehension on the one hand, and among bilinguals themselves on the other. The performance differences between male and female participants, as well as the age factor were also examined. Subjects included English Language Translation students in University of Zanjan (Iran). Monolinguals were Persian speakers, whereas bilinguals were Persian-Turkish speakers. After administering Nelson English Language Test, English Proverb Test, and Yandell's English Idiom Test, the results were analyzed through ANOVA, Independent-samples t-test, and Pearson product-moment correlation. Findings indicated that there was no statistically significant difference in the between-group and within-group performances of monolinguals and bilinguals. However, the results showed that males outperformed females in the idiom test, but not in the proverb test. The existence of a relationship between age and idiom-proverb comprehension was not supported. The findings lent support to the arguments proposed by Cummins's (1976) Threshold Hypothesis - which may thus have some implications for encouraging bilingual education in schools; the findings of this study may also be useful for the curriculum developers and policymakers in multilingual societies.
\end{abstract}

Index Terms - bilingual education, Persian language, English idiom and proverb comprehension, sex-age factor, threshold hypothesis

\section{REVIEW OF PREVIOUS STUDIES}

Bilingual and multi-language use, as Grosjean (1982) points out, is becoming widespread; it also characterizes a bulk of the world population. To be more accurate, as Crystal (1997) estimates, two-thirds of the world's children grow up in bilingual environments. In this regard, Iran is not an exception. Colin and Prys (1998) report a large part of Iranian population to be bilingual in which about $20 \%$ are Turkish speakers.

Research on bilingualism and bilingual education is wide-ranging and has grown noticeably in quantity and quality in recent years; it is often argued that whether knowing more than two languages enhances learning new languages. Hence, its investigation covers an extensive array of pro-bilingual and anti-bilingual inquiries.

On the one hand, some studies (Cenoz \& Valencia, 1994; Cummins, 1979; Eisentein, 1980; Hoffman, 2001; Klein, 1995; Modirkhamane, 2006; Sanz, 2000 and Thomas, 1988) consider bilinguality as advantageous on third language acquisition. For example, Ben-Zeev (1977) compared two groups of Hebrew-English and English children and came to the conclusion that bilinguals outperformed monolinguals on grammaticality judgment tasks. This research is in line with that of Galambos (1982) which proposed that Salvadoran children proficient in English and Spanish demonstrated a stronger syntactic orientation when judging grammatically correct and incorrect sentences in both languages. Eisenstein (1980) carried out a research on the relationship between bilingualism and foreign language learning, the results of which indicated that bilingual children were more prone to learn a foreign language. Lindfors' findings (1991) showed that metalinguistic awareness as an effect of bilingualism is a crucial factor in educational development such as grouping words by parts of speech, word definition, thinking about language forms, recognizing sounds and component syllables of words. 
Likewise, Cook (1997) claimed that foreign language study results in "increased metalinguistic awareness of phonology, syntax, and the arbitrary nature of meaning, and gains in cognitive flexibility" (p. 235). Kaushanskaya and Marian (2009) tried to work out whether or not bilingualism facilitates acquisition of novel words in adults, comparing monolingual English speakers, early English-Spanish bilinguals, and early English-Mandarin bilinguals. They suggested that "acquisition of any two languages early in life facilitates the ability to learn new words in adulthood" (p. 709).

In a study conducted by Thomas (1988), two groups of English monolinguals and English-Spanish bilinguals were compared in learning French. Her study demonstrated striking differences between the two groups, as the bilinguals outperformed the monolinguals. She concluded that bilinguals learning a third language seem to have developed a sensitivity to language as a system which helps them perform better on those activities usually associated with formal language learning as compared to the monolinguals learning a foreign language for the first time. In the same way, Cenoz and Valencia (1994) and Sanz (2000) investigated the influence of bilinguality (mostly balanced and biliterate bilinguals) on third language learning. They found bilinguals' performance on metalinguistic awareness tasks outstanding and disclosed the reason as the consequence of bilingual experience. Similarly, in a longitudinal survey Modirkhamene (2006) examined the possible effects of bilinguality on reading comprehension proficiency achievement. The results indicated that "bilinguals performed significantly better than monolinguals, [and that] bilingualism may be a good predictor of achievement in learning a third language" (p. 280).

On the other hand, some studies (Anastasi \& Cordova, 1953; Darcy, 1953; McNamara, 1966; Nayak et al, 1990; Saer, 1923 and Yousefi, 1995) find bilinguality disadvantageous. Darcy (1953) concluded from a review of related research on intelligence and bilingualism that bilinguals suffer as a language handicap. McNamara (1966) stated that bilingual children never reached comparable levels of linguistic proficiency as did monolinguals and their "lower verbal intelligence was a result of a 'balance effect,' whereby proficiency in a second language necessitated a loss in proficiency in one's first language" (p. 505). Nayak et al. (1990) conducted a research on the acquisition of an artificial grammar by multilinguals, bilinguals and monolinguals. The results showed no clear evidence indicating that multilinguals and bilinguals were superior in language learning abilities. Yousefi (1995) compared Persian and Turkish learners in terms of intelligence and English language achievement. The results indicated that bilinguals did not perform better than monolinguals on intelligence test. He also demonstrated that monolinguals performed better in English language achievement test. He hypothesized the weak performance of bilinguals in illiteracy in first (Turkish) language and argued that "the bilingual children studying foreign languages as a part of their curriculum would fall behind their monolingual classmates. Therefore, providing some extra-curriculum EFL classes for the minority language children seems to be of great help, if not necessary" (p. 54). He maintained that developing first language skills will directly flourish second and foreign languages. Likewise, Bahrainy (2003) found monolinguals' performance better than that of bilinguals. She conducted a research among 150 female subjects and found significant differences between the two groups of Turkish-Persian bilinguals and Persian monolinguals; that is to say, "Monolinguals surpassed bilinguals in both areas of lexicon and syntax" (p. xii).

\section{THE PRESENT STUDY}

The present research attempts to offer a new perspective on some of the issues of bilingualism, proposing a new direction for the bilingual research. The study addresses degrees of bilingualism and argues that parents-child communication (which benefits from a more extensive usage of Turkish language) results in better achievements in proverb-idiom comprehension. Thus a comparison is conducted amid between-groups (monolinguals and bilinguals) and within-groups (bilinguals). Sex and age effect are also investigated. This study also demonstrates a relationship between cross-linguistic experience and figurative language, particularly idiom and proverb.

Idiom and proverb are considered as figurative language because they cannot be meaningful literally. Interpreting them requires a cognitive process made of all the possible meanings entering to the mind. Besides, every society-and consequently every culture-have its own sets of idioms and proverbs. These are mostly context-dependent and vary from culture to culture; this is also true from one language to another.

Some observations in the literature on bilingualism and multilingualism suggest that bilingual children are more flexible in thinking as compared to monolinguals, and that they have greater language awareness. As language has an influence on thoughts and beliefs, people who know more than two languages may have a wider range of thought and a greater command of language. Thus, in order to comprehend and interpret figurative language, the role of crosslinguistic experience seems crucial. This issue is yet to be addressed in the research on bilingualism. The study examines this issue by measuring the English language comprehension of both monolinguals and bilinguals.

Another issue to be considered in bilingualism is its extent. Zanjan is considered a bilingual province among Iran's thirty-one provinces. Azeri (often called Turki/Turkish) is spoken as an informal language, while Persian is spoken and taught as the formal language in schools and universities. Turkish is learned orally and there is no script for it, yet city inhabitants can speak it very well (although they cannot read or write it). Indeed, there is no official and unanimously agreed-upon script for Turkish neither in Zanjan nor in Iran. Thus, the bilinguals are considered as dominate not balanced; furthermore, they go under three categories based on language of communication to their parents: a) the ones who use Persian, b) the ones who use Turkish and c) the ones who use both languages. This study examines ALL three 
categories, highlighting the role of bilinguality on idiom-proverb comprehension (not only between-groups but also within-groups). The age and sex factors of participants are considered as well.

\section{QUESTIONS OF THE STUDY}

1- Is there any significant difference in idiom comprehension scores of bilinguals and monolinguals?

2- Is there any significant difference in proverb comprehension scores of bilinguals and monolinguals?

3 - Is there any significant difference among three groups of bilinguals?

4- Which sex performs better? Females or males?

5- Can age factor be influential?

\section{Methodology}

\section{Participants}

All the subjects in this study were students of English Language Translation in University of Zanjan (a Turkishspeaking city in Iran). Among the whole 126 participants, 91 subjects were distributed into four groups of both female and male. They were selected according to their English proficiency level (intermediate) by a standard test (Nelson English Language Test) and a demographic questionnaire.

Hence, Group $A_{1}$ consisted of Persian monolinguals $(n=20,13$ females and 7 males, mean age $=21.73$ years, $S D=$ 1.58), Group $A_{2}$ Turkish-Persian bilinguals $(n=25,22$ females and 3 males, mean age $=22.32$ years, $S D=2.44)$, Group $\mathrm{A}_{3}$ Turkish-Persian bilinguals $(\mathrm{n}=26,23$ females and 3 males, mean age $=21.55$ years, $\mathrm{SD}=1.57)$, Group $\mathrm{A}_{4}$ Turkish-Persian bilinguals $(\mathrm{n}=20,9$ females and 11 males, mean age $=21.81$ years, $\mathrm{SD}=1.11)$.

The difference between the last three groups is their degree of being bilingual. Consequently, GA2 participants, though knowing Turkish, speak Persian to their parents. $\mathrm{GA}_{3}$ use both languages, and finally $\mathrm{GA}_{4}$ speak Turkish to their parents.

As Fig. 1 shows, the percentage of bilinguals who speak both Turkish and Persian with their parents (GA3) is the highest of all, while the percentage of bilinguals who speak Turkish with their parents is the lowest.

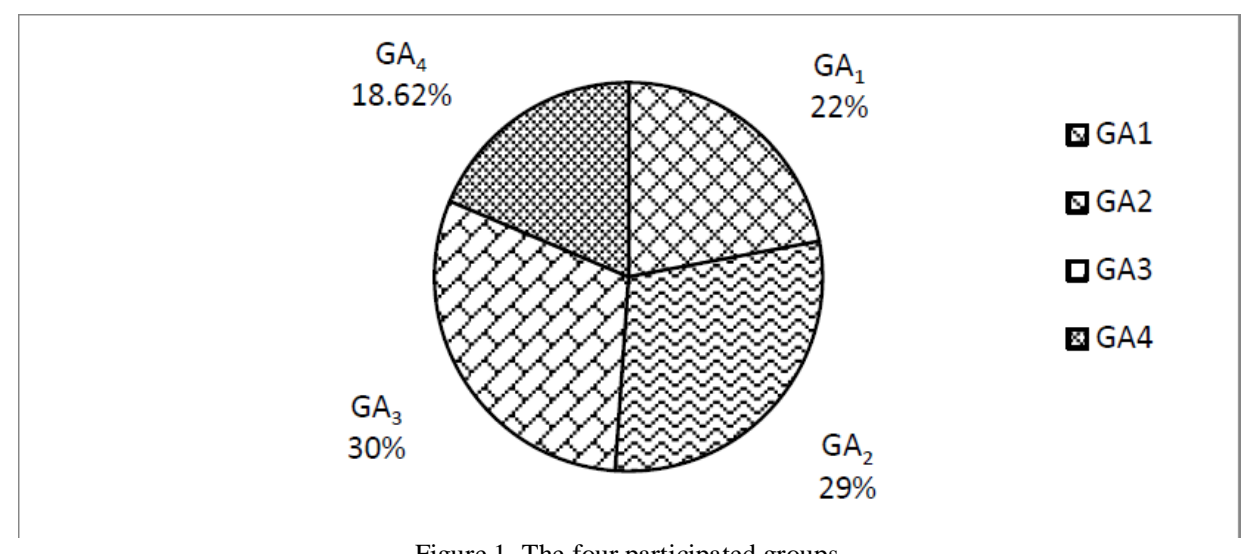

Figure 1. The four participated groups.

\section{Instrumentation}

In order to test the hypotheses, the researchers utilized four tools; Nelson English Language Test, Yandell's Idioms Test, English Language Proverb Test and Demographic Questionnaire.

Being cautious about the homogeneity of participants with respect to English language proficiency level, the researchers decided to administer one of the Nelson English Language Battery of tests (300 D), which is commonly used for three major reasons. First of all, it is quick. Second, it is standard (Cronbach's Alpha is 0.67). It benefits from 50 multiple-choice items and measures the subjects' English language knowledge, focusing on grammar, vocabulary and pronunciation. It took the subjects 45 minutes to respond. The third reason is its practicality. The allocated time for the researchers for each session was limited, while they also wanted the students to fill out the test completely with enthusiasm and willingness.

The idiom test used in this study was first developed by Maurine Yandell in 1959 at the University of New Mexico. Later, it was applied by Esther Amelia Hoiland in 1973 at the University of Saskatchewan, Canada. The estimation of reliability through Cronbach's alpha is 0.75 .

The proverb test used in this study is developed by Santos at Texas Tech University in 2000. It contains twenty-four short stories (e.g., six to ten sentences in length) accompanied by a proverb at the end of the story. The ubjects were asked to choose the general meaning of the proverb which explained it in various situations. The estimation of reliability through Cronbach's alpha was 0.84 .

The main purpose of preparing demographic questionnaire was to sift out participants into four groups based on their knowledge of Persian and Turkish languages. The construction of the questionnaire has benefited a panel of 
professionals in English language teaching. This questionnaire covers items of age, sex, place of residence, mother tongue, father tongue, and the language of communication between parents and subjects.

\section{RESULTS AND DisCUSSION}

Summary descriptive statistics including the performance mean of the subjects are presented in Table 1.

TABLE 1.

DESCRIPTIVE STATISTICS OF IDIOM AND PROVERB TESTS AND AGE OF THE SUBJECTS

\begin{tabular}{llllll}
\hline & Number of Subjects & Minimum & Maximum & Mean & Std. Deviation \\
\hline Idiom Test & 86 & 4 & 27 & 12.22 & 4.528 \\
Proverb Test & 86 & 4 & 23 & 14.05 & 4.937 \\
Age & 84 & 19 & 31 & 21.90 & 1.788 \\
\hline
\end{tabular}

As Table 2 shows, there is no significant difference in scores for monolinguals $(\mathrm{M}=12.84, \mathrm{SD}=4.79)$ and the ones for bilinguals, $\mathrm{M}=12.04, \mathrm{SD}=4.47 ; \mathrm{t}(84)=0.67, \mathrm{p}=0.50$ (two-tailed). The magnitude of the differences in the means (mean difference $=0.79,95 \% \mathrm{CI}$ : -1.55 to 3.14 ) is very small (eta squared $=.005$ ) according to Cohen's rating (1988, cited in Pallant, 2007).

TABLE 2:

INDEPENDENT SAMPLES T-TEST FOR YANDELL'S IDIOMS TEST

\begin{tabular}{|c|c|c|c|c|c|c|c|c|c|}
\hline & \multicolumn{2}{|c|}{$\begin{array}{l}\text { Levene's Test for } \\
\text { Equality of Variances }\end{array}$} & \multicolumn{7}{|c|}{ t-test for Equality of Means } \\
\hline & $\mathrm{F}$ & Sig. & $\mathrm{t}$ & df & $\begin{array}{l}\text { Sig. } \\
\text { (2-taild) }\end{array}$ & $\begin{array}{l}\text { Mean } \\
\text { Difference }\end{array}$ & $\begin{array}{l}\text { Std. Error } \\
\text { Difference }\end{array}$ & $\begin{array}{l}95 \% \mathrm{C} \\
\text { the Dif }\end{array}$ & ce Interval of \\
\hline & & & & & & & & Lower & Upper \\
\hline $\begin{array}{l}\text { Equal variances } \\
\text { assumed }\end{array}$ & 0.061 & 0.806 & 0.674 & 84 & 0.501 & 0.797 & 1.181 & -1.551 & 3.145 \\
\hline $\begin{array}{l}\text { Equal variances not } \\
\text { assumed }\end{array}$ & & & 0.649 & 27.494 & 0.522 & 0.797 & 1.229 & -1.722 & 3.317 \\
\hline
\end{tabular}

Table 3 reveals no significant difference in scores for monolinguals $(\mathrm{M}=13.21, \mathrm{SD}=4.99)$ and bilinguals, $\mathrm{M}=$ 14.28, $\mathrm{SD}=4.93 ; \mathrm{t}(84)=-0.83 . \mathrm{p}=0.40$ (two-tailed). The magnitude of the differences in the means (mean difference $=-1.07,95 \%$ CI: -3.62 to 1.48 ) is very small (eta squared $=.008$ ) according to Cohen's rating (1988, cited in Pallant, 2007).

TABLE 3.

INDEPENDENT SAMPLES T-TEST FOR PROVERB TEST

\begin{tabular}{|c|c|c|c|c|c|c|c|c|c|}
\hline \multirow{5}{*}{$\begin{array}{l}\text { Equal variances } \\
\text { assumed } \\
\text { Equal variances not } \\
\text { assumed }\end{array}$} & \multicolumn{2}{|c|}{$\begin{array}{l}\text { Levene's Test for } \\
\text { Equality of Variances }\end{array}$} & \multicolumn{7}{|c|}{ T-test for Equality of Means } \\
\hline & $\mathrm{F}$ & Sig. & $\mathrm{t}$ & df & $\begin{array}{l}\text { Sig. } \\
\text { (2-taild) }\end{array}$ & $\begin{array}{l}\text { Mean } \\
\text { Difference }\end{array}$ & $\begin{array}{l}\text { Std. Error } \\
\text { Difference }\end{array}$ & $\begin{array}{l}95 \% \mathrm{C} \\
\text { of the I }\end{array}$ & $\begin{array}{l}\text { ce Interval } \\
\text { ce }\end{array}$ \\
\hline & \multirow{3}{*}{0.039} & \multirow{3}{*}{.844} & & & & & & Lower & Upper \\
\hline & & & -.835 & 84 & 0.406 & -1.073 & 1.286 & -3.629 & 1.48 \\
\hline & & & -.829 & 28.730 & .414 & -1.073 & 1.295 & -3.722 & 1.576 \\
\hline
\end{tabular}

The bar charts illustrated in Fig. 2 provide a clear overview of monolinguals' and bilinguals' mean scores in idiomproverb comprehension. In idiom test monolinguals performed slightly better than bilinguals, while in proverb test bilinguals performed better than monolinguals. 


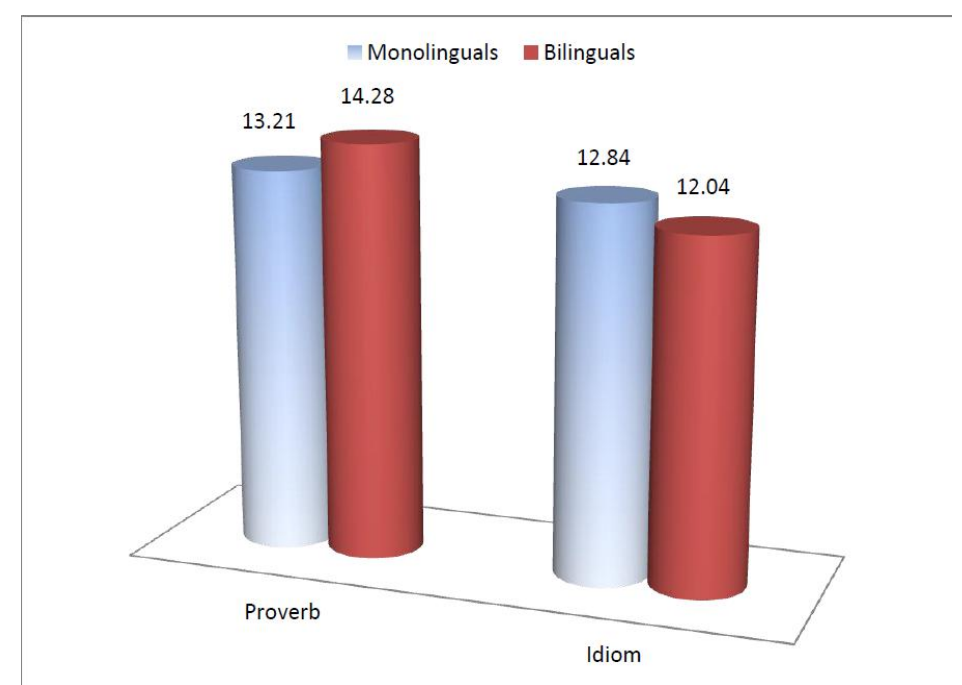

Figure 2. Comparison of bilinguals and monolinguals on idiom and proverb tests.

In order to answer the third question, One-Way ANOVA seemed to be a suitable option. Table 4 presents differences among three groups of bilinguals regarding the idiom test performance. Degree of freedom equals 2 and as F $(2,64)=$. 23 and less than 3.14, the null hypothesis cannot be rejected. Here, the p-value (.79) is higher than .05 at the level of 95 percent probability. The calculated $\mathrm{n}^{2}=.007$ which is a very small effect, indicating that only .7 percent of the variance in idiom comprehension is explained by Turkish language.

TABLE 4.

DIFFERENCES AMONG GROUPS IN YANDELL'S IDIOMS TEST

\begin{tabular}{lllllll}
\hline & Sum of squares & df & Mean square & f & sig. & Partial eta squared \\
\hline BETWEEN & 9.417 & 2 & 4.709 & 0.230 & 0.795 & 0.007 \\
GROUPS & 1309.448 & 64 & 20.460 & & & \\
WITHIN GROUPS & 1318.866 & 66 & & & & \\
TOTAL & & & & & \\
\hline
\end{tabular}

Table 5 shows the differences among three groups of bilinguals in reference to proverb test performance. Degree of freedom equals 2 and as $F(2,64)=1.34$ and less than 3.14 , the null hypothesis cannot be rejected. The p-value $(.26)$ is higher than .05 at the level of 95 percent probability. As a result, there is no significant difference among bilinguals themselves. The calculated $\mathrm{\eta}^{2}$ (partial eta squared) equals .04 which is a small effect, signifying that only 4 percent of the variance in proverb comprehension is explained by Turkish language.

TABLE 5.

DIFFERENCES AMONG GROUPS IN PROVERB TEST

\begin{tabular}{lllllll}
\hline & Sum of squares & df & Mean square & f & sig. & Partial eta squared \\
\hline Between groups & 64.730 & 2 & 32.365 & 1.344 & 0.268 & .040 \\
Within groups & 1540.882 & 64 & 24.076 & & & \\
Total & 1605.612 & 66 & & & & \\
\hline
\end{tabular}

Fig. 3 displays the mean differences - though not significant - among bilinguals themselves, illustratively.

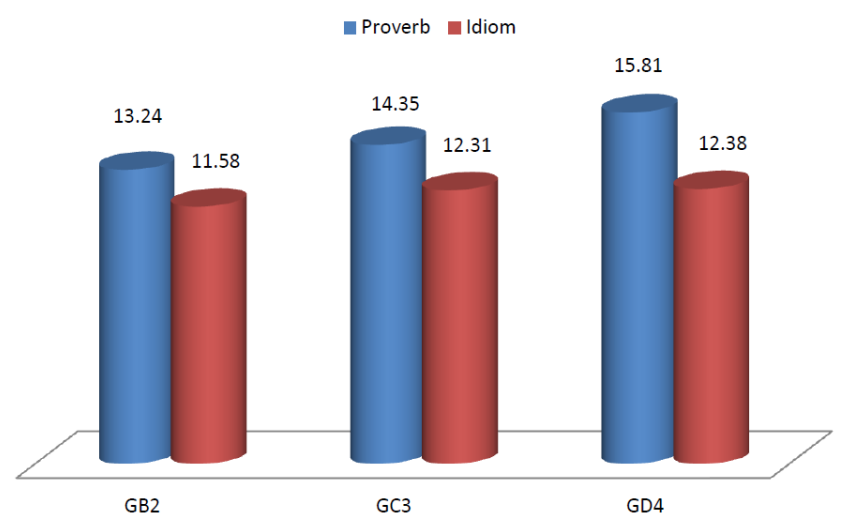

Figure 3. Comparison of three groups of bilinguals on idiom and proverb tests. 
In order to answer the fourth research question, an Independent Samples T-test was used. In Table 6, t-value equals 2.31, degree of freedom equals 84 and p-value equals .02. For the calculated t in comparison to T-table (2.00) with the probability of 5 percent is greater and $\mathrm{p}<.05$ which induces that another null hypothesis of this study is rejected.

TABLE 6.

INDEPENDENT SAMPLES T-TEST FOR YANDELL'S IDIOMS TEST

\begin{tabular}{|c|c|c|c|c|c|c|c|c|c|}
\hline \multirow{5}{*}{$\begin{array}{l}\text { Equal variances } \\
\text { assumed } \\
\text { Equal variances not } \\
\text { assumed }\end{array}$} & \multicolumn{2}{|c|}{$\begin{array}{l}\text { Levene's Test for } \\
\text { Equality of Variances }\end{array}$} & \multicolumn{7}{|c|}{ T-test for Equality of Means } \\
\hline & $\mathrm{F}$ & Sig. & $\mathrm{t}$ & df & $\begin{array}{l}\text { Sig. } \\
\text { (2-taild) }\end{array}$ & $\begin{array}{l}\text { Mean } \\
\text { Difference }\end{array}$ & $\begin{array}{l}\text { Std. Error } \\
\text { Difference }\end{array}$ & $\begin{array}{l}95 \% \mathrm{C} \\
\text { of the I }\end{array}$ & $\begin{array}{l}\text { ence Interval } \\
\text { ence }\end{array}$ \\
\hline & \multirow{3}{*}{0.066} & \multirow{3}{*}{.798} & & & & & & Lower & Upper \\
\hline & & & 2.312 & 84 & 0.023 & 2.488 & 1.076 & 0.348 & 4.628 \\
\hline & & & 2.104 & 33.319 & 0.043 & 2.488 & 1.182 & .083 & 4.893 \\
\hline
\end{tabular}

As Table 7 indicates, $(p=.06$ and $p>.05)$ there is no significant difference between males and females in proverb test. None of the two groups performed superior. In Table 4.13, t-value equals 1.84, degree of freedom equals 84 and pvalue equals .06. For the calculated $t$ in comparison to T-table (2.00) with the probability of 5 percent is smaller and $\mathrm{p}>.05$ - which indicates that the null hypothesis is confirmed. In contrast to idiom test, males did not perform better than females in proverb comprehension test.

TABLE 7.

INDEPENDENT SAMPLES T-TEST FOR PROVERB TEST

\begin{tabular}{|c|c|c|c|c|c|c|c|c|c|}
\hline \multirow{5}{*}{$\begin{array}{l}\text { Equal variances } \\
\text { assumed } \\
\text { Equal variances not } \\
\text { assumed }\end{array}$} & \multicolumn{2}{|c|}{$\begin{array}{l}\text { Levene's Test for } \\
\text { Equality of Variances }\end{array}$} & \multicolumn{7}{|c|}{ T-Test for Equality of Means } \\
\hline & $\mathrm{F}$ & Sig. & $\mathrm{t}$ & df & $\begin{array}{l}\text { Sig. } \\
\text { (2-taild) }\end{array}$ & $\begin{array}{l}\text { Mean } \\
\text { Difference }\end{array}$ & $\begin{array}{l}\text { Std. Error } \\
\text { Difference } \\
\end{array}$ & $\begin{array}{l}95 \% \mathrm{C} \\
\text { the Dif } \\
\end{array}$ & ce Interval of \\
\hline & & & & & & & & Lower & Upper \\
\hline & 0.230 & 0.633 & 1.848 & 84 & 0.068 & 2.192 & 1.168 & -0.167 & 4.550 \\
\hline & & & 1.790 & 36.932 & .082 & 2.192 & 1.224 & -0.289 & 4.673 \\
\hline
\end{tabular}

Fig. 4 illustrates the differences between males and females in both tests of idiom and proverb.

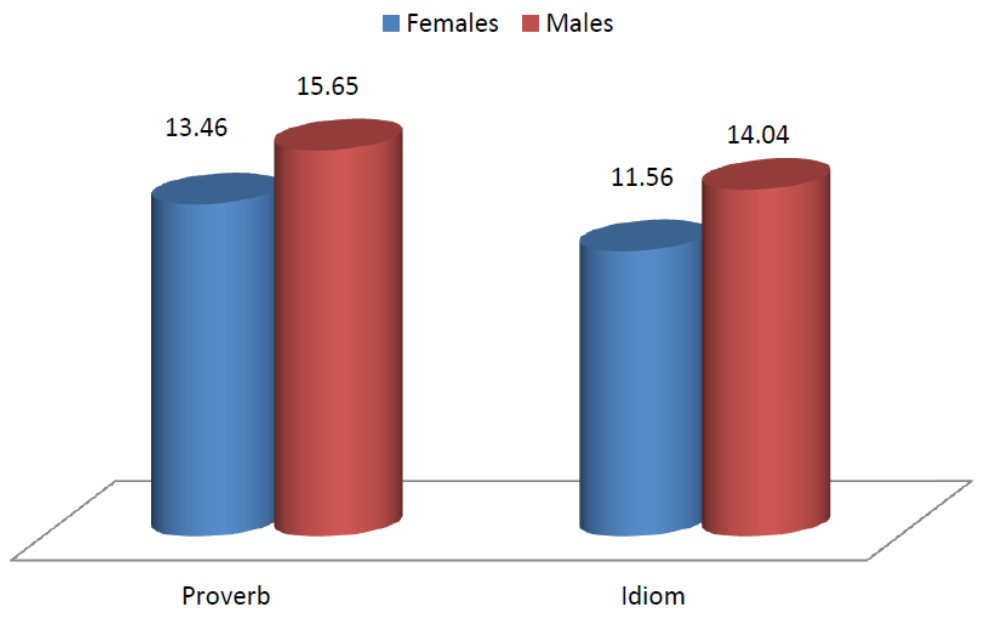

Figure 4. Comparison of females and males on idiom and proverb tests.

In order to answer the last question, Pearson Product-Moment Correlation was used to explore the relationship between age (19 to 31 years old) and idiom comprehension score.

In Table 8 the estimated correlation $(r)$ is .13 , indicating a small correlation. As $\mathrm{p}=.23$ and $\mathrm{p}>.05$, there is no significant relationship between age and idiom comprehension. 
TABLE 8.

PEARSON PRODUCT-MOMENT CORRELATION

\begin{tabular}{llll}
\multicolumn{3}{c}{} & PEARSON PRODUCT-MOMENT CORRELATION \\
\hline \multirow{2}{*}{ Age } & Pearson Correlation & Age & Idiom \\
& Sig. (2-tailed) & 1 & 0.132 \\
& $\mathrm{~N}$ & & 0.232 \\
\cline { 2 - 4 } Idiom & Pearson Correlation & 84 & 84 \\
& Sig. (2-tailed) & 0.132 & 1 \\
& $\mathrm{~N}$ & 0.232 & 86 \\
\hline
\end{tabular}

In order to explore the relationship between age and proverb score, again Pearson Product-Moment Correlation was applied since both variables were interval and continuous. As Table 9 shows, estimated correlation (r) is .07, indicating a very small correlation. As $\mathrm{p}=.51$ and $\mathrm{p}>.05$, there is no significant relationship between age and proverb comprehension.

TABLE 9.

PEARSON PRODUCT-MOMENT CORRELATION

\begin{tabular}{llll}
\multicolumn{4}{c}{ PEARSON PRODUCT-MOMENT CORRELATION } \\
\hline \multirow{4}{*}{ Age } & Pearson Correlation & Age & Idiom \\
& Sig. (2-tailed) & 1 & 0.073 \\
& $\mathrm{~N}$ & & 0.510 \\
\cline { 2 - 3 } Idiom & Pearson Correlation & 84 & 84 \\
& Sig. (2-tailed) & 0.073 & 1 \\
& $\mathrm{~N}$ & 0.510 & 86 \\
\hline
\end{tabular}

\section{CONCLUSION}

In order to find answers for the role of cross-linguistic experience and discover whether it has an effect on English language comprehension, particularly idiom and proverb, among the 86 participants - all English language translation students at the University of Zanjan, Iran - the Persian monolingual were sieved from the Persian-Turkish bilinguals. Some of the questions addressed in this study may be original in the sense that first, the study highlighted the degree of bilingualism in: a) dominant bilinguals, whose language to communicate to their parents is Persian, b) dominant bilinguals, who communicate to their parents through Turkish, and c) dominant bilinguals, whose language to communicate to their parents are both Persian and Turkish. Second, the study sought to find answers in the realm of English proverb and idiom, which is a novel issue in studies on bilingualism.

Taken together, the findings lent support the hypothesis that bilinguality cannot be considered as an enhancement or a hindrance in learning the third language (English). Nevertheless, high proverb mean differences of bilinguals in comparison to monolinguals, as well as high proverb-idiom mean differences among bilinguals themselves imply the fact that bilinguality may have a positive role if bilinguals' mother tongue attains a certain level of proficiency (i.e. learning mother tongue academically). This statement is line with Cummins's (1976) Threshold Hypothesis which assumes that individual bilinguals will not benefit from their bilinguality until they have attained a certain minimum or threshold level of competence in a second language. He also points out that balanced bilinguals show positive effects when various aspects of cognitive development are measured. Dominant bilinguals would show neither positive nor negative effects, i.e. their achievement will not differ from that of monolinguals. Those, on the other hand, who achieve a native level in neither of their languages would perform at a lower level as compared to monolingual children.

With regard to the sex factor, the results of independent samples T-test revealed the fact that males' performance on idiom comprehension was more significant than that of females. This result was true for proverb comprehension [the mean score of males (15.56) was greater than females (13.46)] but not statistically significant.

With regard to the sex factor, a small correlation yielded. It can be concluded that age factor is irrelevant to idiomproverb comprehension as senior students did not perform better than freshman students.

One implication of the report may be said to be the significance of bilingual education in order to let bilingual children benefit from the privilege of their mother tongue. In Iran for example, curriculum developers and policy makers of the Ministry of Education are encouraged to design and assign courses in Turkish language. Dube and Herbert (1975) found that school performance and linguistic proficiency in both languages increases when children's mother tongue is valued and used in the classroom. Furthermore, from a social point of view, bilingual education would help society benefit from enhanced linguistic resources in its political, economical, and international relations.

To take a step further, bilingual education may encourage parents to raise their children bilingually. This may help Turkish language (which is indeed in danger of extinction) to regain its position among the Persian-Turkish families. This fact is in line with researchers who support learning a language earlier, including Zied et al. (2004, p. 256) who argue that "the more proficient in a certain language a person is being young, the more proficient he will remain in that language being older." Also, De Bot (2006) reports the study which Mechelli et al. conducted on Italian learners of English in 2004 suggesting that "there is an increase of density [gray matter density in the inferior parietal cortex] with language learning and a decline with the increase of age of onset of acquisition" (p.128). Another implication for the this study is for English language teachers to consider more seriously the teaching of idiom and proverb; presenting 
them comparatively, the teachers can observe the cultural differences for the sake of a more effective teaching. Extensive exposure and systematic practice can be beneficial.

\section{REFERENCES}

[1] Anastasi, A. \& Cordova, F. (1953). Some effects of bilingualism upon the intelligence test performance of Puerto Rican children in New York City. Journal of Educational Psychology 44, 1- 9.

[2] Bahrainy, N. (2003). The impact of bilinguality on third language acquisition: A UG-based approach. Ph.D. dissertation, University of Tehran.

[3] Ben-Zeev, S. (1977). The influence of bilingualism on cognitive strategy and cognitive development. Child Development 48, 1009-1018.

[4] Cenoz, J., \& Valencia, F. J. (1994). Additive trilingualism: Evidence from the Basque country. Applied Psycholinguistics 15, 195-207.

[5] Colin, B. \& Prys, J. S. (1998). Encyclopedia of bilingualism and bilingual education. Clevedon, UK: Multilingual Matters. Retrieved from http://drsetayesh.vcp.ir (accessed 10/8/2010).

[6] Cook, V. (1997). The consequences of bilingualism for cognitive processing. In A. M. De Groot, \& J. F. Kroll (eds.), Tutorials in bilingualism: Psycholinguistic perspectives. Mahwah, NJ: Lawrence Erlbaum Associates, 279-299.

[7] Crystal, D. (1997). English as a global language. Cambridge, UK: Cambridge University Press.

[8] Cummins, J. (1976). The influence of bilingualism on cognitive growth: A synthesis of research findings and explanatory hypothesis. Working Papers on Bilingualism 9, 1-43.

[9] Cummins, J. (1979). Linguistic interdependence and the educational development of bilingual children. Review of Educational Research 49.2, 222-51.

[10] Darcy, N. J. (1953). A review of the literature on the effects of bilingualism upon the measurement of intelligence. The Journal of Genetic Psychology 82.1, 21-57.

[11] De Bot, K. (2006). The plastic bilingual brain: Synaptic pruning or growth? Commentary on Green et al. In M. Gullberg; \& P. Indefrey (eds.), The cognitive neuroscience of second language acquisition. USA: Blackwell Publishing, 127-132.

[12] Dubé, N. C. \& Herbert, G. (1975). Evaluation of the St John Valley Title VII bilingual education program, 1970-1975. Unpublished report. Madawaska, Maine.

[13] Eisenstein, M. (1980). Childhood bilingualism and adult language learning aptitude. International Review of Applied Psychology 29.1-2, 159-172.

[14] Galambos, S. (1982). The development of metalinguistic awareness in bilingual and monolingual children. Paper presented at the Seventh Annual Boston University Conference on Language Development, Boston.

[15] Grosjean, F. (1982). Life with two languages: An introduction to bilingualism. Cambridge, MA: Harvard University Press.

[16] Hoffman, C. (2001). Towards a description of trilingual competence. International Journal of Bilingualism 5.1, 1-17.

[17] Hoiland, E. A. (1973). Interpretation of English idioms by Indian and non-Indian children. Published M.A. thesis. Saskatchewan University.

[18] Kaushanskaya, M. \& Marian, V. (2009). The bilingual advantage in novel word learning. Psychonomic Bulletin \& Review 16.4, 705-710.

[19] Klein, E.C. (1995). Second versus third language acquisition: Is there a difference? Language Learning 45.3, 419-465.

[20] Liontas, J. I. (2002). Exploring second language learners: Notions of idiomaticity. System 30.3, 289-313.

[21] Macnamara, J. (1966). Bilingualism and primary education. Edinburgh: Edinburgh University Press.

[22] Mechelli, A., Crinion, J.T., Noppeney, U. \& et al. (2004). Neurolinguistics: structural plasticity in the bilingual brain. Nature 431.7010, 757-757.

[23] Modirkhamane, S. (2006).The reading achievement of third language versus second language learners of English in relation to the interdependence hypothesis. International Journal of Multilingualism 3.4, $280-295$.

[24] Nayak, H., Hansen, N., Krueger, N., \& Mclaughlin, B. (1990). Language learning strategies in monolingual and multilingual adults. Language Learning 40.2, 221-244.

[25] Pallant, J. (2007). SPSS survival manual: A step by step guide to data analysis using SPSS for Windows. Maidenhead: Open University Press.

[26] Saer, O.J. (1923). The effect of bilingualism on intelligence. British Journal of Psychology 14, 25-28.

[27] Santos, I. De Los. (2000 ). Proverb comprehension among bilingual preadolescents and adolescents. M.S. thesis, Texas Tech University Health Sciences Center.

[28] Sanz, C. (2000). Bilingual education enhances third language acquisition: Evidence from Catalonia. Applied Psycholinguistics 21.1, 23-44.

[29] Thomas, J. (1988). The role played by metalinguistics awareness in second and third language learning. Journal of Multilingual and Multicultural Development 9.3, 235-247.

[30] Yousefi, V. (1995). The role of bilingualism in cognitive development and foreign language learning. M. A. thesis, University of Tehran.

[31] Zied, K. M. \& et al. (2004). Bilingualism and adult differences in inhibitory mechanisms: Evidence from a bilingual stroop task. Brain and Cognition 54.3, 254-256.

[32] Zobl, H. (1993). Prior linguistic knowledge and the conservation of the learning procedure: Grammaticality judgments of unilingual and multilingual learners. In S.M. Gass and L. Selinker (eds.), Language Transfer in Language Learning. Amsterdam: John Benjamins, 176-196. 
Behnaz Moein got her M.A. in TEFL and her B.A. in English Language Translation from the University of Zanjan, Iran. She currently teaches in the University of Zanjan and the Applied-Science University. Her academic interests include bilingualism, language acquisition, socio-cultural aspects of teaching and learning, sociolinguistics, applied linguistics, language learning strategies and teacher education.

Robab Khosravi obtained her Ph.D. in English Literature from Keele University, United Kingdom. She is currently Assistant Professor and the Head of the English Language Department at University of Zanjan, Iran. Her main research interests are Modernism, the twentieth-century poetry (the work of T. S. Eliot in particular), critical theory, and aspects of postmodern thought and culture.

Hooshang Yazdani is Assistant Professor of TEFL in Department of English Language and Literature in Arak University, Iran. He studied a new way of evaluating EFL readers reading comprehension abilities for his MA Degree and investigated the effects of different variables on reading strategy choice and comprehension for his Ph.D. Degree in Essex University, United Kingdom. He has taught different courses related to language and linguistics for about twenty years. His research interests lie mainly in reading comprehension, evaluating reading comprehension, reading strategy, evaluation, discourse analysis, critical discourse analysis, language teaching methodology, and to some extent in psycholinguistics. 